\title{
1 Model-based evaluation of a trickling filter facility upgrade to biological
}

\section{2 nutrient removal}

3 Rubén Díez-Montero ${ }^{\mathrm{a}, b^{*}}$, María Castrillo $^{\mathrm{a}}$, Marta $\mathrm{Casao}^{\mathrm{c}}$, Iñaki Tejero ${ }^{\mathrm{a}}$

$4 \quad{ }^{\mathrm{a}}$ Department of Water and Environmental Sciences and Technologies, University of Cantabria,

5 ETS Ingenieros de Caminos, Canales y Puertos, Avda. Los Castros s/n, 39005 Santander, Spain

$6 \quad{ }^{\mathrm{b}}$ Department of Civil and Environmental Engineering, Universitat Politècnica de Catalunya, c/

7 Jordi Girona 1-3, Building D1, E-08034 Barcelona, Spain

$8{ }^{c}$ FCC Aqualia, FCC Servicios Ciudadanos, c/ Federico Salmón 13 Planta 2, 28016 Madrid,

9 Spain

$10{ }^{*}$ Corresponding author e-mail: ruben.diez.montero@upc.edu

11

12 


\section{Abstract}

14 This article presents the feasibility evaluation and preliminary design of a wastewater treatment plant upgrade supported by simulation. The existing facility was based on trickling filters, and the objective of the upgrade was to achieve nutrients removal. The proposed solution modifies the existing primary clarifier to host an anaerobic-anoxic suspended growth reactor, which is an alternative that, to our knowledge, has not been proposed or explored so far. The trickling filters would remain as aerobic reactors. In this study, the novel treatment scheme has been assessed for the first time, through model simulations. The modified treatment train was simulated, showing that the anoxic zone is able to denitrify satisfactorily achieving the required effluent nitrogen concentration. However, to promote biological phosphorus removal, an additional aerobic zone combined with a bypass of activated sludge from the anoxic zone to the first trickling filter is needed, in order to provide aerobic conditions to the phosphate accumulating organisms. Several combinations of additional aerobic volume and sludge bypass flowrate were found to successfully achieve both nitrogen and phosphorus removal, using the existing facilities without the need for new reactors neither implementing modifications that could put the trickling filters' physical integrity at risk. The novel treatment scheme could be applied in other cases with similar flowsheet in the same context.

31 Keywords: trickling filter retrofitting; modeling and simulation; anaerobic-anoxic biological reactor; nitrogen removal; enhanced biological phosphorus removal; integrated process 


\section{Introduction}

Nitrogen and phosphorus are the main nutrient elements discharged along with wastewaters, whose presence in the receiving water bodies significantly contributes to eutrophication. The need for nutrient removal is pursued by stringent regulation for the protection of water bodies, such as Directive 91/271/EEC in Europe. In addition, due to the reviews of the water quality objectives, there is an increased number of areas being declared as sensitive to eutrophication which, therefore, require nitrogen and phosphorus removal from wastewater before it is discharged into such areas (European Union, 1991; European Union, 2000). This fact implicates a need for upgrades or retrofits of a significant number of wastewater treatment plants (WWTP) for nutrient removal. Conventional configurations for biological nutrient removal (BNR) require anaerobic and anoxic compartments, in addition to aerobic ones, which must be large enough to establish nitrification. This results in a substantial increase in the complexity of wastewater treatment configurations when compared to those needed for organic matter removal only.

Facilities based on trickling filters (TF) have been widely used in many countries for organic matter removal. TFs' inherent advantages include operational simplicity, resistance to toxic and shock loads, and low energy requirements (Daigger and Boltz, 2011). These features make TF facilities suitable for small and medium-sized communities, as the case presented in this paper. Many TF facilities have been upgraded because they have become undersized due to increasing influent loadings. Generally, these upgrades consist on incorporating suspended growth reactors, giving place to combined or coupled processes, such as the $\mathrm{TF} /$ solids contact $(\mathrm{TF} / \mathrm{SC})$ and the roughing filter/activated sludge (RF/AS) (Harrison, 2017). However, those processes are inherently aerobic processes, facing only organic matter removal and in some cases nitrification. Examples and studies about TF/SC and RF/AS processes are presented in Harrison et al. (1984), Harrison and Lum (1994) and Harrison (2017). 
For total nitrogen removal, facilities must be upgraded for denitrification as well, which can be achieved by means of pre or post-anoxic suspended growth or biofilm reactors (Mehlhart, 1994). Vanhooren et al. (2003) observed that at high organic loading rates with insufficient oxygen supply to the biofilm, denitrification could be induced in TFs by providing the biofilm with external nitrate. Indeed, several full-scale case studies have been reported in the literature using TFs for denitrification. Dorias and Baumann (1994) reported three cases in Germany where TFs were modified for denitrification: the TFs were covered and the aeration openings were impounded. Successful results are presented, comparable to those obtained by pre-anoxic denitrification in the activated sludge process. Nasr et al. (2000) presented the upgrade of the WWTP of Salisbury (Maryland), in which a TF was flooded to provide anoxic conditions for denitrification. The preliminary tests results were successful, however, due to the lack of backwashing and air scour, the biofilm grew excessively and the desired denitrification performance was not achieved. Eventually, when the anoxic TF was drained to take it out-ofservice, the media support collapsed due to the biofilm weight without the buoyant force of water in the tank. Manzano et al. (2018) presented the upgrade of a medium-sized WWTP in southern England, where a pre-denitrification submerged anoxic filter was installed downstream the primary settling and prior to the TFs. Different operational strategies were studied, achieving successful nitrogen removal. In a different approach, Dai et al. (2013) integrated pre-anoxic denitrification in a primary settling tank to enhance nitrogen removal in a TF facility. By recycling the nitrified effluent from the TF to the primary settling tank, an improvement of nitrogen removal was achieved through denitrification in the activated settling tank.

Regarding phosphorus removal, biological processes are preferred over chemical ones, due to the lower operational cost. Indeed, the application of innovative processes for chemical phosphorus removal from TF effluents, such as electrocoagulation, has shown not to be a feasible alternative to conventional processes (Stafford et al., 2014). Therefore, additional anaerobic tanks are 
needed for enhanced biological phosphorus removal (EBPR). Moreover, alternate anaerobicaerobic/anoxic conditions are required to promote the growth of phosphate accumulating organisms (PAO), responsible for EBPR. Few studies have been found that address both nitrogen and phosphorus biological removal at full-scale TF facilities. Most of them have proposed the extension of the TF process with additional anaerobic, anoxic and aerobic activated sludge tanks (Christensen, 1991; Morgan et al., 1999) or converting the TFs into suspended growth reactors (Dichtl et al., 1994).

In the case study presented in this paper, the objective of the upgrading is to achieve nitrogen and phosphorus effluent standards, and the primary constraint for the process selection is the limited available space. It should also be considered that the WWTP serves a medium-sized community of fewer than 20,000 inhabitants, so that alternatives involving low investment and operating costs would be prioritized. In this framework, a number of alternatives were proposed and preliminarily analyzed in order to upgrade the existing facility to nutrient removal. The first alternative, consisting of post-anoxic denitrification in biofilters and chemical precipitation of phosphorus, corresponds to conventional and consolidated technology and makes it possible to reach a good quality effluent. However, the main drawbacks of this alternative are the implementation of an additional post-treatment, and the need for an external carbon source and chemical addition for denitrification and phosphorus precipitation, respectively. These facts would imply a high investment and operational cost.

Another alternative was pre-anoxic denitrification, which could be carried out in the first TF or in the primary clarifier. Those possibilities do not require an external carbon source addition and do not imply the construction of new tanks or reactors for nitrogen removal, but, as a drawback, phosphorus should be removed by chemical precipitation. In order to avoid the use of chemicals, and therefore reduce the operational cost, a plant extension including anaerobic suspended 
108 growth reactors was proposed, in order to provide alternating anaerobic-aerobic/anoxic 109 conditions to promote the growth of PAO.

110 Specifically, the ultimate alternative proposed consists of a modification of the existing primary

111 clarifier to host an anaerobic-anoxic sludge blanket reactor. The main goals of this alternative are

112 to achieve BNR (i.e. no need for chemicals and low sludge production) and to reuse the existing 113 facilities (i.e. no need for construction of new tanks or reactors). These goals entail a low

114 investment and operational cost compared to conventional upgrade alternatives. In spite of the 115 apparent suitability of such a process there is no literature in the state-of-the-art reporting similar 116 configurations. The possibility of reusing primary clarifiers and converting them into activated 117 anaerobic-anoxic reactors for biological removal is an alternative that, to our knowledge, has not 118 been proposed or explored so far in attempts to upgrade TF facilities. In addition, the proposed 119 modification is inspired in a patent of the authors (Tejero et al., 2010) that allows combining 120 anaerobic-anoxic zones and clarifying functionality in the same reactor, which would cover the 121 aforementioned proposed goals. If feasible, the proposed configuration could be applied in many 122 other cases with similar flowsheet in the same context. Nonetheless, the hypothesis of achieving 123 the proposed goals with the conversion of the primary clarifier to an anaerobic-anoxic reactor 124 should be tested prior to full-scale implementation. A model-based approach is proposed for the 125 feasibility evaluation and preliminary design of the facility upgrade. The capabilities of 126 mathematical models for assessing and comparing different alternatives have proven their 127 usefulness to make decisions about existing facilities' retrofits (Hvala et al., 2002; Mucha and 128 Mikosz, 2016). Model simulations have been shown to be useful for the design, optimization and 129 upgrading of WWTP, aiding to estimate the optimal design configuration, reactor sizes and 130 operational strategies, and providing an estimation of the expected response (Daigger and 131 Nolasco, 1995; Salem et al., 2002; Seco et al., 2004; Guerrero et al., 2011; Chen et al., 2018; 
132 Kroiss and Klager, 2018). Furthermore, modeling is of particular interest in BNR processes due

133 to the large number of interacting phenomena.

134 The objective of this paper is to assess the feasibility and to preliminarily design and optimize a

135 novel process for the retrofitting of an existing TF WWTP to BNR, by means of mathematical 136 model simulations. This study is a required preliminary step prior to the real full-scale 137 implementation, in order to assess the feasibility of the proposed solution, avoiding or reducing 138 the risk and uncertainty of classical and conventional design procedures. The configuration of 139 this novel process consists of an anaerobic-anoxic sludge blanket reactor, hosted in the existing 140 primary clarifier, followed by the existing TFs and clarifiers.

\section{2. Methodology}

\section{$142 \quad$ 2.1. Case study}

143 The existing WWTP began operations in 2005. It serves a Spanish community with a population

144 of approximately 15,000 inhabitants, discharging into the Ebro river basin. The wastewater 145 treatment scheme, consisting of a two-stage TF process with intermediate clarification, is shown

146 in Figure 1. The process consists of pretreatment (5-mm screening and grit removal), primary 147 clarification, first stage $\mathrm{TF}$, intermediate clarification, second stage $\mathrm{TF}$ and secondary 148 clarification. The TFs are filled with a random plastic media type (specific surface area $100 \mathrm{~m}^{2}$ $149 \mathrm{~m}^{-3}$; void space 95\%), occupying a volume of $3,181 \mathrm{~m}^{3}$ in each filter. The three clarifiers 150 (primary, intermediate and secondary) are identical, with an individual volume of $1,823 \mathrm{~m}^{3}$.

151 The influent and effluent annual average available data are summarized in Table 1. These values, 152 provided by the public company Navarra de Infraestructuras Locales S.A. (NILSA, Gobierno de

153 Navarra), were obtained from the operation of the WWTP during a whole year. Satisfactory 154 organic matter removal and nitrification were achieved, while denitrification and phosphorus 155 removal did not occur. The new discharge permit requires both nitrogen and phosphorus removal 


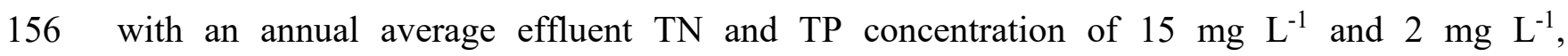

157 respectively, according to European regulation Directive 91/271/EEC, for treatment plants of

158 less than 100,000 population equivalent discharging into sensitive areas.

159

160

161

162

163

164

165

166

167

168

169

170

171

172

173

174

175

176

177

178

179

\subsection{Process description}

The proposed configuration is based on the reuse of the existing primary clarifier to accommodate an anaerobic-anoxic sludge blanket reactor, as depicted in Figure 2(A). The overall proposed treatment scheme, shown in Figure 2(B), claims that both nitrogen and phosphorus biological removal using the existing facilities avoids the construction of new tanks or reactors, does not require an external carbon source or chemicals addition, and does not imply modifications that could put the TFs' physical integrity at risk.

At first glance, the primary clarifier volume, with an average hydraulic retention time (HRT) of $8.4 \mathrm{~h}$, seems to be large enough to hold the anaerobic and anoxic zones. The anaerobic-anoxic modified primary clarifier (MPC) would provide the environmental conditions needed for phosphate release and denitrification (with its corresponding uptake of organic matter), while the existing TFs would provide the aerobic stage for the removal of remaining organic matter, phosphate uptake and nitrification. Mainly, the first TF is aimed at organic matter removal and phosphate uptake, operating as a hybrid process (biofilm and suspended biomass coexisting in the same reactor), while the second filter is aimed at nitrification.

Coupling the existing TFs with a suspended biomass reactor (the MPC) leads to an integrated process. It has the additional advantage of enabling separate control of both the slower-growing nitrifying biomass, which usually prefers to reside on biofilms, and the faster-growing heterotrophic biomass including denitrifiers and PAO, which would reside in the suspended activated sludge. This feature facilitates the optimization of simultaneous nitrogen and phosphorus removal processes (Onnis-Hayden et al., 2011). 
180 The modification of the primary clarifier is based on an anaerobic-anoxic sludge blanket reactor

181 for BNR, named AnoxAn, which was proposed by Tejero et al. (2010). The AnoxAn reactor was

182 conceived with the objective of unifying the anaerobic and anoxic zones of a wastewater

183 treatment process for BNR in a single reactor, aimed at achieving high compactness and

184 efficiency. A clarification zone at the top of the reactor avoids the escape of large amounts of

185 biomass, thus promoting high sludge concentration in a sludge blanket type reactor. Moreover,

186 simultaneous denitrification and phosphate uptake could be achieved. Overall, the AnoxAn

187 configuration claims anaerobic phosphate release, anoxic denitrification and phosphate uptake in

188 a single reactor. Its hydrodynamic and biological feasibility was demonstrated in an upflow

189 AnoxAn prototype (Díez-Montero et al., 2015; Díez-Montero et al., 2016).

190 However, in this case study, due to the shape and dimensions of the primary clarifier (26 $\mathrm{m}$

191 diameter and $3.0 \mathrm{~m}$ depth), a concentric configuration was proposed instead of a vertically

192 compartmentalized upflow reactor, which in addition is expected to provide a simplification of

193 the hydrodynamic behavior. The primary clarifier modification can be implemented by means of

194 a cylindrical inner wall dividing the clarifier into two different zones: (i) central anaerobic zone

195 with a volume of $800 \mathrm{~m}^{3}$, and (ii) outer anoxic zone with a volume of $1,013 \mathrm{~m}^{3}$. The influent

196 wastewater is fed into the anaerobic zone, where it is mixed with activated sludge recycled from

197 the anoxic zone (anoxic recycle, AR). A submersible mixer would provide mixing in the

198 anaerobic zone, and the mixed liquor would flow to the anoxic zone through openings in the

199 upper part of the cylindrical inner wall. A nitrate rich stream recycled from the second TF

200 (nitrate recycle, NR) would enter the anoxic zone together with the sludge recycled from the

201 intermediate clarifier (return activated sludge, RAS), where submersible mixers provide

202 intermittent mixing. The effluent would then be withdrawn through submerged outlet tubes.

203 Underneath the outlet tubes, a set of lamellas would be assembled to provide a final clarification 
zone. The intermittent mixing in the anoxic zone would, therefore, cause settling cycles, which together with the lamellas, would aid to reduce the amount of biomass escaping from the MPC.

Inside the MPC, the biomass would alternate anaerobic and anoxic environmental conditions, so that denitrifying PAO would be promoted. Furthermore, a certain amount of activated sludge would be bypassed (sludge bypass, SB) from the anoxic zone to the first stage TF in order to provide aerobic conditions to the PAO and enhance the phosphorus removal efficiency. The simulated SB, expressed as a percentage of the influent flowrate, covered a range from 0 to $50 \%$.

211 Finally, the inclusion of an aerobic zone in the MPC has also been considered, correspondingly 212 reducing the available anoxic volume. This additional aerobic volume would be needed to 213 improve the EBPR and to achieve the desired phosphorus removal efficiency. The aeration could 214 be performed in a specific volume of the anoxic zone, by means of submerged air diffusers, 215 therefore reducing the actual anoxic volume. Several aerobic volumes (AV) have been 216 simulated, from $100 \mathrm{~m}^{3}$ to $800 \mathrm{~m}^{3}$ (accordingly reducing the anoxic volume), which correspond 217 to $9.8 \%$ to $78.2 \%$ of the original anoxic volume. Besides, aeration could be carried out

218 continuously or intermittently, depending on the oxygen demand. Therefore, the process would 219 provide flexibility to control the addition of electron acceptors depending on influent 220 characteristics.

\section{2.3. Mathematical model}

222 A model of the current secondary treatment WWTP was implemented in BioWin Process 223 Simulator v4.0 (EnviroSim Associates Ltd., Ontario, Canada), as shown in Figure 3(A). The 224 biological processes were described according to the BioWin General Model (ASDM), which 225 has fifty state variables and sixty process expressions, including ordinary heterotrophic biomass 226 activity under aerobic and anoxic conditions, nitrification (ammonium oxidation and nitrite 227 oxidation), and enhanced biological phosphorus removal. For details on parameters description 
and process expressions, the reader is referred to the BioWin user manual (freely available on the internet).

A TF process flowsheet element is included in BioWin v4.0, which can be configured for various media packing types and characteristics. In the model, the depth of the TF is divided into three equal layers to simulate oxygen levels and removal gradients from top to bottom. The biofilm model used in BioWin is a 1D model as described by Wanner and Reichert (1996) and Reichert and Wanner (1997). For details on fundamental equations, the reader is referred to those documents. The settling tanks were implemented as ideal clarifiers. The influent wastewater characteristics were adopted from the available data, including total and soluble COD, $\mathrm{TN}, \mathrm{NH}_{4}-$ $\mathrm{N}, \mathrm{NO}_{3}-\mathrm{N}, \mathrm{NO}_{2}-\mathrm{N}, \mathrm{TP}$ and TSS. Further fractionation of the influent characteristics was obtained 238 using the BioWin default parameters.

239 In this case study, typical municipal wastewater with negligible industrial contribution is treated 240 in the WWTP, and the environmental conditions are not extreme. Within this context, it was 241 expected that the default model parameters would not need to be significantly modified. 242 Nonetheless, steady-state simulation results were compared with the annual average operational 243 results of the WWTP shown in Table 1. Some model parameters were adjusted in order to 244 improve the agreement between predicted results (simulations) and operating results in the 245 existing secondary treatment, based on a trial and error method as in Simsek et al. (2012). 246 Afterwards, the model was modified to represent the proposed upgrade for BNR, as shown in 247 Figure 3(B), without modifying the model parameters neither the influent wastewater 248 characteristics. In order to represent the physical upgrades, the primary clarifier was divided into 249 two chambers to host the anaerobic and anoxic zones, or three chambers to host also the aerobic 250 one. A final settling tank was included at the end of the MPC, to represent the clarification zone. 251 The AR from the anoxic to the anaerobic zone and the NR from the second TF to the anoxic 252 zone were set to 2 and 3 times the influent flowrate, respectively, while the RAS from the 
253 intermediate clarifier to the anoxic zone flowrate was set equal to the SB. The excess sludge 254 waste was adjusted in order to achieve suitable biomass concentration in the MPC in the 255 simulations, compared to conventional activated sludge systems, not exceeding TSS 256 concentration of approximately $3 \mathrm{~g} \mathrm{~L}^{-1}$. The biomass concentration in the MPC was kept 257 reasonably similar in all the simulations, allowing to compare the different scenarios under 258 similar conditions.

259 A set of steady-state simulations has been performed covering a range of different configurations 260 and operational conditions: Run001-Run011 for different SB; Run101-Run188 for different 261 combinations of additional aerobic volume (AV) and SB; and Run201-Run207 for different 262 dissolved oxygen (DO) concentration in the additional aerobic zone, as shown in Table 2.

\section{3. Results and Discussion}

\subsection{Simulation of the current WWTP}

The steady-state effluent quality predicted by the model with the default values of the model parameters was slightly better compared to the effluent quality observed during operation of the WWTP. Therefore, five model parameters were adjusted in order to fit the real plant behavior: ammonium oxidizing bacteria maximum specific growth rate and half-saturation coefficient, ordinary heterotrophic organisms anoxic yield, phosphorus content in biomass, and phosphorus content in the endogenous residue, as shown in Table 3. Through this parameters adjustment, the 271 model nitrifying and denitrifying activities and the biological phosphate uptake were reduced.

272 Therefore, the adjusted model avoids overly optimistic simulation results, being on the safe side. 273 Being aware that it cannot be considered a complete model calibration, the simulated effluent 274 matched pretty well the real average effluent concentrations. The acceptance criteria were a 275 difference lower than $5 \mathrm{mg} \mathrm{L}^{-1}$ for TSS, $10 \%$ for total and soluble COD, and $1 \mathrm{mg} \mathrm{L}^{-1}$ for NT, $276 \mathrm{NH}_{4}-\mathrm{N}, \mathrm{NO}_{3}-\mathrm{N}, \mathrm{TP}$, as proposed in Water Environment Federation (2013). Default values of the 277 biofilm model (number of biofilm layers, liquid boundary layer thickness, and attachment and 
detachment parameters) were kept unchanged, since there were no experimental data to adjust them and the simulation results fulfilled the acceptance criteria.

3.2. Performance of the anaerobic-anoxic modified primary clarifier with sludge bypass to the first trickling filter

The adjusted model was used to simulate the modified WWTP. It should be pointed out that the modified treatment train includes suspended growth reactors, but since there are not real operating results with suspended biomass, it has not been possible to calibrate the model parameters for such biomass. The proposed treatment train has not been implemented in the existing secondary treatment WWTP. Therefore, no experimental data regarding the novel treatment train are available. The previously adjusted parameters have been used in order to avoid overly optimistic results, remaining on the conservative side and keeping the uncertainty within the limits to provide trustworthy results.

The overall effluent quality obtained with the modified treatment train is displayed in Table 4, along with the MPC effluent nitrate concentration and the TSS concentration in the hybrid TF, and in the anaerobic and anoxic zones of the MPC. Satisfactory nitrogen removal was achieved with effluent $\mathrm{TN}$ concentration lower than $15 \mathrm{mgN} \mathrm{L}^{-1}$ in all of the simulated scenarios. Nitrate

294 concentration in the MPC effluent resulted in being negligible $\left(<0.1 \mathrm{mgN} \mathrm{L}^{-1}\right)$, confirming that 295 pre-anoxic denitrification performed successfully in the MPC, which could be attributed to a sufficiently high anoxic HRT (4.7 h) with moderate suspended sludge concentration (up to 2,869 $\operatorname{mgTSS~} \mathrm{L}^{-1}$ ). However, increasing the bypass of biomass from the anoxic zone to the first stage 298 TF resulted in an increase of the effluent TN concentration. Effluent ammonium concentration 299 rose from $2.9 \mathrm{mgN} \mathrm{L}^{-1}$ (Run001) to $6.6 \mathrm{mgN} \mathrm{L}^{-1}$ (Run011), denoting that nitrification was 300 adversely affected. For this reason, configurations with SB above $50 \%$ of the influent flowrate 301 were not simulated. 
The lower nitrification efficiency obtained for higher SB is attributed to the increasing

303 particulate and soluble COD concentration in the nitrifying TF influent (second stage TF). The importance of maintaining low influent suspended solids and biodegradable organic matter to achieve good performance in nitrifying TFs has been previously reported (Parker et al., 1989; Parker et al., 1995; Mofokeng et al., 2009; Dai et al., 2013). In these investigations, it has been 307 suggested that the influence of influent biodegradable organic matter on nitrification is due to the 308 development of a heterotrophic population, which competes with the nitrifiers for oxygen, 309 thereby reducing nitrification rates. For instance, Parket et al. (1989) and Mofokeng et al. (2009) 310 reported that influent biodegradable soluble COD concentration higher than $30 \mathrm{mg} \mathrm{L}^{-1}$ could 311 promote such competition. The simulations showed that the influent biodegradable soluble COD 312 to the nitrifying TF (second stage) ranged from $33.9 \mathrm{mg} \mathrm{L}^{-1}$ (Run001) to $38.5 \mathrm{mg} \mathrm{L}^{-1}$ (Run011), 313 which are slightly higher than the threshold reported by Parker et al. (1989) and Mofokeng et al. 314 (2009). The organic loading rate to the nitrifying TF was increased compared to the one obtained 315 with the existing WWTP flowsheet. Such an increase, regarding biodegradable soluble COD 316 loading rate, ranged from 2.5 (Run001) to 3.9 (Run011) times the loading rate in the existing 317 WWTP, which was detrimental to nitrification. In addition, the $\mathrm{BOD}_{5}$ and $\mathrm{TKN}$ volumetric 318 loading rates recommended by the German standard for the dimensioning of TFs with 319 nitrification were exceeded in the second stage TF in runs with SB above 15\% (Run005320 Run011), confirming the inability to perform successful nitrification (DWA, 2001). According to 321 this standard, the dimensioning of trickling filters should sum the volumes corresponding to 322 organic matter removal and nitrification, obtained with the relevant parameters $0.4 \mathrm{kgBOD}_{5} \mathrm{~m}^{-3}$ $323 \mathrm{~d}^{-1}$ and $0.1 \mathrm{kgTKN} \mathrm{m}^{-3} \mathrm{~d}^{-1}$, respectively.

324 Regarding phosphorus removal, the desired effluent TP concentration was not achieved in any 325 simulation and was not improved by increasing SB. Negligible phosphate release in the 326 anaerobic zone (results not shown) confirmed that EBPR would not take place. It is considered 
that the influent wastewater was not carbon deficient, according to the high $\mathrm{C} / \mathrm{N}$ ratio

$328(\mathrm{COD} / \mathrm{TN}=14)$, and the aforementioned excessive organic loading rate, so that the inability to achieve EBPR was attributed to the short HRT under aerobic conditions in the hybrid TF (first stage). Taking into account that the volume of water in a TF corresponds only to a thin layer trickling over the support media and the biofilm, the actual residence time of wastewater (and

332 suspended biomass) in TFs is relatively low compared to other types of hybrid processes. For 333 instance, the HRT in integrated fixed film activated sludge (IFAS) reactors corresponds to the 334 total volume of the reactor, which is in the range of hours.

3.3. Performance of the anaerobic-anoxic modified primary clarifier with additional

337 In order to increase the aerobic HRT for the suspended growth biomass, an additional aerobic 338 reactor should be included in the treatment train. Due to the large size of the primary clarifier 339 and the excellent denitrification capability shown in the aforementioned simulations, the use of a 340 section of the anoxic zone of the MPC to provide aerobic conditions is proposed. In order to 341 represent the aerobic zone, an additional aerobic reactor has been included in the model next to

342 the anoxic one, with a DO concentration of $2.0 \mathrm{mg} \mathrm{L}^{-1}$. This alternative has been assessed in 343 combination with the SB previously discussed. A range of combinations (AV - SB) was 344 analyzed. Three-dimensional surface plots of the effluent TN and TP concentrations for each 345 combination of AV and SB are shown in Figure 4. It can be observed that most of the scenarios 346 analyzed fulfill the required effluent quality. The effluent $\mathrm{TN}, \mathrm{NH}_{4}-\mathrm{N}, \mathrm{NO}_{3}-\mathrm{N}$ and $\mathrm{TP}$ 347 concentrations, $\mathrm{NO}_{3}-\mathrm{N}$ concentration in the MPC effluent, and TSS concentration in the 348 anaerobic zone, anoxic zone and hybrid (first stage) TF, for each simulation (Run101-Run188), 349 can be found in Supplementary Information (Table S1).

350 Excellent nitrogen removal was obtained, with an effluent TN concentration lower than $15 \mathrm{mgN}$ $351 \mathrm{~L}^{-1}$ in all of the simulated scenarios. However, the extent of nitrification and denitrification 
varied depending on the $\mathrm{AV}$ - SB combination. Without the additional aerobic zone, it was previously discussed how nitrification was deteriorated as the SB was increased, due to an excessive organic loading into the nitrifying TF (second stage). This issue was improved by including an aerobic zone in the anoxic zone of the MPC, where a certain amount of organic matter was removed. An AV as small as $100 \mathrm{~m}^{3}$ (corresponding to $9.8 \%$ of the original anoxic volume) was enough to reduce the biodegradable soluble COD loading rate into the nitrifying TF by $25.5 \%$ compared to the simulations without $\mathrm{AV}$, as well as to fulfill the $\mathrm{BOD}_{5}$ and $\mathrm{TKN}$ volumetric loading rates recommended by the German standard for dimensioning of TFs with nitrification (DWA, 2001). Larger AV volumes provided higher organic loading decreases. Furthermore, it was observed that an aerobic volume higher than $48.9 \%$ of the original anoxic volume had an adverse effect on denitrification, thereby increasing the nitrate concentration in the MPC effluent (up to $4.3 \mathrm{mgN} \mathrm{L}^{-1}$ ) and the $\mathrm{TN}$ concentration in the overall effluent (up to $11.7 \mathrm{mgN} \mathrm{L}^{-1}$ ). In such scenarios, denitrification was not complete, which was attributed to the reduced anoxic volume wherein the aerobic zone replaced more than $48.9 \%$ of the original anoxic volume. Under the conditions of the present case study, the minimum anoxic volume that guarantees suitable denitrification is $523 \mathrm{~m}^{3}$, which provides an HRT of $2.4 \mathrm{~h}$ and corresponds to an aerobic occupancy of $48.9 \%$ of the original anoxic volume. Therefore, the implementation of large aerobic volumes is not recommended on account of the fact that the TN effluent quality is slightly deteriorated due to the reduction of denitrification ability.

Regarding phosphorus removal, effluent TP concentration exceeded $2 \mathrm{mgP} \mathrm{L}^{-1}$ in several runs, all of them characterized by low AV and/or low SB. This indicates that EBPR could not be achieved by means of only SB or only AV. When no additional AV was implemented, the EBPR failure was attributed to the reduced aerobic HRT provided for suspended biomass in the TF. On the other hand, when an excessively large AV was added, the increasing nitrate concentration in the anoxic zone due to incomplete denitrification led to nitrate recycle into the anaerobic zone, 
hampering or avoiding the occurrence of EBPR. Nonetheless, excellent phosphorus removal was achieved by the combination of AV and SB. The effluent TP concentration was reduced as both the AV and the SB were increased, and eventually, most of the scenarios analyzed provided an effluent TP concentration below $2 \mathrm{mgP} \mathrm{L}^{-1}$. This effluent TP concentration came along with significant phosphate release in the anaerobic zone (results not shown), thus confirming the occurrence of EBPR, which was attributed to the increase of the aerobic HRT for suspended biomass, provided by the combination of the hybrid TF (first stage) and the additional AV included in the MPC.

Overall, a broad range of combinations of AV and SB was found to fulfill the required removal

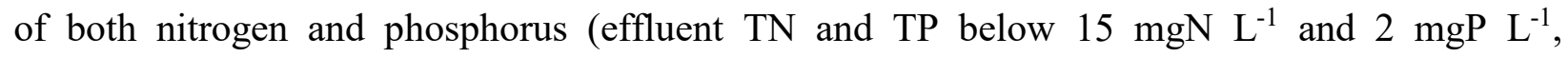
387 respectively) using the existing facilities, without the construction of new tanks or reactors. This 388 range is depicted in green in Figure 5. Moreover, there is an optimal range of combinations AV $389 \mathrm{SB}$ able to achieve more restrictive requirements (effluent $\mathrm{TN}$ and TP below $10 \mathrm{mgN} \mathrm{L}^{-1}$ and 1 $390 \mathrm{mgP} \mathrm{L} \mathrm{L}^{-1}$, respectively), which is displayed in light green in Figure 5. In addition, biomass 391 concentration in the anoxic/aerobic zone ranged between 2,475 and 3,107 $\mathrm{mgTSS} \mathrm{L}^{-1}$, which 392 appears to be moderate enough to allow for a final clarification of the MPC effluent.

393 Finally, in order to optimize the aeration in the additional aerobic volume, further simulations 394 have been performed reducing the DO concentration in the aerobic zone from $2.0 \mathrm{mg} \mathrm{L}^{-1}$ to 0.01 395 $\mathrm{mg} \mathrm{L}^{-1}$ (Run201-207). The configuration implemented in Run140 (39.1\% of AV and 30\% of SB) 396 has been selected as one of the optimal solutions and has been used as the basis for the following 397 simulations. Results are depicted in Figure 6.

398 Excluding the simulations with 0.02 and $0.01 \mathrm{mg} \mathrm{L}^{-1}$, it was observed that the effluent TN and 399 TP concentrations were similar to those obtained with DO concentration of $2.0 \mathrm{mg} \mathrm{L} \mathrm{L}^{-1}$. BNR 400 performed successfully with DO concentration as low as $0.1 \mathrm{mg} \mathrm{L}^{-1}$, while it was deteriorated 401 when the DO was further reduced due to the loss of nitrification and the reduction of PAO 
activity, similarly to the simulations without aerobic zone. These results imply that the aerobic reactor could be operated with low DO concentration and support the viability of including the aerobic zone inside the anoxic zone by means of intermittent aeration of a partial volume of the anoxic zone. The DO concentration could be controlled to a low set point during the aeration period, thereby allowing oxygen transfer efficiency to be optimized and the energy requirement 407 reduced, therefore reducing the operational cost of the additional aerobic zone.

\section{Conclusions}

The upgrading of an existing secondary treatment TF WWTP to achieve BNR is proposed and assessed through model simulations. The proposal is based on the modification of the existing

411 primary clarifier to host an anaerobic-anoxic sludge blanket reactor, and therefore to provide the conditions required for BNR. By means of this facility upgrade, BNR resulted feasible by using

413 the existing facilities in the current WWTP, without the addition of any new tanks neither 414 implementing modifications that could put the TFs' physical integrity at risk. The proposed 415 treatment train upgrade would be advantageous from the economic point of view, reducing both 416 the investment and operational cost compared to conventional upgrade alternatives.

417 Nitrogen removal was successfully achieved in all the simulated scenarios, with TN effluent 418 concentration below $15 \mathrm{mgN} \mathrm{L}^{-1}$. The anoxic zone in the modified primary clarifier performed 419 satisfactorily, and proper denitrification was maintained reducing the anoxic HRT up to $2.4 \mathrm{~h}$. 420 Further reduction of the anoxic volume led to incomplete denitrification.

421 Biological phosphorus removal was not achieved by solely alternating anaerobic and anoxic 422 conditions. A reduction of the anoxic volume to host an additional aerobic zone in the same 423 modified primary clarifier, in combination with the bypassing activated sludge from the anoxic 424 zone to the first stage TF, in order to provide aerobic conditions to the PAO biomass, was found 425 to achieve EBPR successfully. Several combinations of aerobic volume - sludge bypass obtained 
426 a TP effluent concentration below $2 \mathrm{mg} \mathrm{L}^{-1}$, while maintaining excellent nitrogen removal.

427 Furthermore, there is an optimal range of combinations of aerobic volume and sludge bypass 428 able to achieve more restrictive requirements (effluent TN and TP below $10 \mathrm{mgN} \mathrm{L}^{-1}$ and $1 \mathrm{mgP}$ $429 \mathrm{~L}^{-1}$, respectively).

\section{Acknowledgments}

431 The authors are grateful to Marta González for their helpful comments and suggestions.

432 Funding: This work was supported by the Spanish Ministry of Economy and Competitiveness 433 and the European Regional Development Fund (FEDER) [project BBi $^{2}$ CTM2012-36227; and 434 the network of excellence RedNovedar CTQ2014-51693-REDC]. R. Díez-Montero would like to 435 thank the Spanish Ministry of Industry and Economy for his research grant (FJCI-2016-30997).

\section{References}

437 Chen, Q.; Wang, Q.; Yan, H.; Chen, C.; Ma, J.; Xu, Q. (2018) Improve the performance of full438 scale continuous treatment of municipal wastewater by combining a numerical model and online 439 sensors. Wat. Sci. Tech., Vol. 78, No. 8, pp. 1658-1667.

440 Christensen, K. (1991) Extension of a large trickling filter plant for combined nitrogen and 441 phosphorus removal (Ejby Mølle Wastewater Treatment Plant, Odense, Denmark). Wat. Sci. 442 Tech. Vol. 23, pp. 791-800.

443 Dai, Y.; Constantinou, A.; Griffiths, P. (2013) Enhanced nitrogen removal in trickling filter 444 plants. Wat. Sci. Tech. Vol. 67, No. 10, pp. 2273-2280.

445 Daigger, G. T.; Boltz, J. P. (2011) Trickling Filter and Trickling Filter-Suspended Growth 446 Process Design and Operation: A State-of-the-Art Review. Water Environ. Res. Vol. 83, No. 5, 447 pp. 388-404.

448 Daigger, G. T.; Nolasco, D. (1995) Evaluation and design of full-scale wastewater treatment 449 plants using biological process models. Water Sci. Tech. Vol 31, No. 2, pp. 245-255. 
450 Dichtl, N.; Engelhardt, N.; Firk, W.; Koppetsch, J. (1994) Conventional and unconventional 451 integration of trickling filters in a process for BNR. Wat. Sci. Tech. Vol. 29, No. 12, pp. 81-88.

452 Díez-Montero, R.; De Florio, L.; González-Viar, M.; Volcke, E. I. P.; Tejero, I. (2015) 453 Feasibility of hydraulic separation in a novel anaerobic-anoxic upflow reactor for biological 454 nutrient removal. Bioprocess and Biosyst. Eng. Vol. 38, No. 1, pp. 93-103.

455 Díez-Montero, R.; De Florio, L.; González-Viar, M.; Herrero, M.; Tejero, I. (2016). Performance 456 evaluation of a novel anaerobic-anoxic sludge blanket reactor for biological nutrient removal 457 treating municipal wastewater. Bioresour. Technol. Vol. 209, pp. 195-204.

458 Dorias, B.; Baumann, P. (1994) Denitrification in trickling filters. Wat. Sci. Tech. Vol. 30, No. 6, 459 pp. 181-184.

460 DWA (2001) Standard ATV-DVWK-A 281E: Dimensioning of Trickling Filters and Rotating 461 Biological Contactors. DWA German Association for Water, Wastewater and Waste: Hennef, 462 Germany.

463 European Union (1991) Council Directive 91/271/EEC of 21 May 1991 concerning urban 464 wastewater treatment. Official Journal L 135, 30/05/1991, pp. 0040-0052.

465 European Union (2000) Directive 2000/60/EC of the European Parliament and of the Council of 46623 October 2000 establishing a framework for Community action in the field of water policy. 467 Official Journal L 327, 22/12/2000, pp. 0001-0073.

468 Guerrero, J.; Guisasola, A.; Vilanova, R.; Baeza, J.A. (2011) Improving the performance of a 469 WWTP control system by model-based setpoint optimisation. Environ. Modell. Softw., Vol. 26, $470 \quad$ pp. $492-497$.

471 Harrison, J. R. (2017) Coupling Trickling Filter or RBC's with Activated Sludge. Fixed Film 472 Forum, Articles \& Facts, accessed online www.fixedfilm forum.com. Water Environment 473 Federation: Alexandria, Virginia. 
474 Harrison, J. R.; Daigger, G. T.; Filbert, J. W. (1984) A survey of combined trickling filter and 475 activated sludge processes. J. Water Pollut. Control Fed. Vol. 56, No. 10, pp. 1073-1079.

476 Harrison, J. R.; Lum, L. W. K. (1994) Trickling Filter Solids Contact: Operation and 477 Nitrification. Proceedings of the 67 th Annual Conference \& Exposition WEFTEC'94; Chicago, 478 Illinois, Oct 15-19; Water Environment Federation: Alexandria, Virginia.

479 Hvala, N.; Vrečko, D.; Burica, O.; Stražar, M.; Levstek, M. (2002) Simulation study supporting 480 wastewater treatment plant upgrading. Wat. Sci. Tech. Vol. 46, No. 4-5, pp. 325-332.

481 Kroiss, H.; Klager, F. (2018) How to make a large nutrient removal plant energy self-sufficient. 482 Latest upgrade of the Vienna Main Wastewater Treatment Plant (VMWWTP). Wat. Sci. Tech., 483 Vol. 77, No. 10, pp. 2369-2376.

Manzano, I.; Dias, J.S.; Cannon, J.; Soares, A. (2018) Optimization of a full-scale site to achieve 485 total nitrogen removal through implementation of a denitrification-submerged anoxic filter. 486 Water Environ. J., Vol. 32, pp. 242-249.

487 Mehlhart, G. F. (1994) Upgrading of existing trickling filter plants for denitrification. Wat. Sci. 488 Tech. Vol. 30, No. 6, pp. 173-179.

489 Mofokeng, T.; Muller, A. W.; Wentzel, M. C.; Ekama, G. A. (2009) Full-scale trials of external 490 nitrification on plastic media nitrifying trickling filter. Water SA Vol. 35, No. 2, pp. 204-210.

491 Morgan, S.; Farley, R.; Pearson, R. (1999) Retrofitting an existing trickling filter plant to BNR 492 standard - Selfs Point, Tasmania’s First. Wat. Sci. Tech. Vol. 39, No. 6, pp. 143-150.

493 Mucha, Z; Mikosz, J (2016) A simulation study of the energy-efficient options for upgrading and 494 retrofitting a medium-size municipal wastewater treatment plant. Environ. Technol., Vol. 37, No. 495 19, pp. 2516-2523. 
Nasr, S. M.; Hankins, W. D.; Messick, C.; Winslow, D. (2000) Full scale demonstration of an innovative trickling filter BNR process. Proceedings of the Water Environment Federation, WEFTEC 2000; Anaheim, California, Oct 14-18; Water Environment Federation: Alexandria, Virginia, pp. 95-111(17).

Onnis-Hayden, A.; Majed, N.; Schramm, A.; Gu, A. Z. (2011) Process optimization by 501 decoupled control of key microbial populations: Distribution of activity and abundance of 502 polyphosphate-accumulating organisms and nitrifying populations in a full-scale IFAS-EBPR 503 plant. Water Res. Vol. 45, No. 13, pp. 3845-3854.

504 Parker, D.S.; Lutz, M.; Andersson, B.; Aspegren, H. (1995) Effect of operating variables on 505 nitrification rates in trickling filters. Water Environ. Res. Vol. 67, No. 7, pp. 1111-1118.

506 Parker, D. S.; Lutz, M.; Dahl, R.; Bernkopf, S. (1989) Enhancing reaction rates in nitrifying 507 trickling filters through biofilm control. J. Water Pollut. Control Fed. Vol. 61, No. 5, pp. 618508631.

509 Reichert, P.; Wanner, O. (1997) Movement of solids in biofilms: significance of liquid phase 510 transport. Wat. Sci. Tech., Vol. 36, No. 1, pp. 321-328.

511 Salem, S.; Berends, D.; Heijnen, J. J.; van Loosdrecht, M. C. M. (2002) Model-based evaluation 512 of a new upgrading concept for N-removal. Wat. Sci. Tech. Vol. 45, No. 6, pp. 169-176.

513 Seco, A.; Ferrer, J.; Serralta, J.; Ribes, J.; Barat, R.; Bouzas, A. (2004) Use of Biological and 514 Sedimentation Models for Designing Peñíscola WWTP. Environ. Technol. Vol. 25, No. 6, pp. $515 \quad 681-687$.

516 Simsek, H.; Kasi, M.; Wadhawan, T.; Bye, C.; Blonigen, M.; Khan, E. (2012) Fate of dissolved 517 organic nitrogen in two stage trickling filter process. Water Res., Vol. 46, pp. 5115-5126.

518 Stafford, B.; Dotro, G.; Vale, P.; Jefferson, B.; Jarvis, P. (2014) Removal of phosphorus from 519 trickling filter effluent by electrocoagulation. Environ. Technol., Vol. 35, No. 24, pp. 3139-3146. 
520 Tejero, I.; Díez, R.; Esteban, A. L.; Lobo, A.; Temprano, J.; Rodríguez, L. (2010) Reactor

521 biológico anóxico-anaerobio para la eliminación de nutrientes de aguas residuales (Anoxic522 anaerobic biological reactor for nutrient removal from wastewater). Spanish Patent ES2338979 523 (in Spanish).

524 Vanhooren, H.; De Pauw, D.; Vanrolleghem, P. A. (2003) Induction of denitrification in a pilot525 scale trickling filter by adding nitrate at high loading rate. Wat. Sci. Tech. Vol. 47, No. 11, pp. $526 \quad 61-68$.

527 Wanner, O.; Reichert, P. (1996) Mathematical modeling of mixed-culture biofilms. Biotechnol. 528 Bioeng., Vol. 49, pp. 172-184.

529 Water Environment Federation (2013) Wastewater Treatment Process Modeling, MOP 31, 530 Second Edition. Manuals of Practice of the Water Environment Federation, McGraw-Hill. ISBN: $531978-0071798426$. 
Figure captions:

534 Figure 1 - Wastewater treatment scheme of the existing WWTP

535 Figure 2 - (A) Primary settling tank modification to anaerobic-anoxic sludge blanket reactor, and

536 (B) Wastewater treatment scheme of the WWTP upgrading for BNR

537 Figure 3 - BioWin flowsheet of: (A) the existing WWTP; and (B) the modified treatment train

538 Figure 4 - Simulated effluent TN (left) and TP (right) concentration for each combination of 539 aerobic volume (AV) and sludge bypass (SB)

540 Figure 5 - Range of simulated combinations of aerobic volume and sludge bypass fulfilling the 541 required effluent quality (green, $\mathrm{TN}<15 \mathrm{mgN} \mathrm{L}^{-1}$ and $\mathrm{TP}<2 \mathrm{mgP} \mathrm{L}^{-1}$ ) and more restringing 542 requirements (light green, $\mathrm{TN}<10 \mathrm{mgN} \mathrm{L}^{-1}$ and $\mathrm{TP}<1 \mathrm{mgP} \mathrm{L}^{-1}$ )

543 Figure 6 - Simulated overall effluent $\mathrm{TN}, \mathrm{NH}_{4}-\mathrm{N}$ and $\mathrm{TP}$ concentration, MPC effluent $\mathrm{NO}_{3}-\mathrm{N}$ 544 concentration, and $\mathrm{PO}_{4}-\mathrm{P}$ concentration in the anaerobic zone, versus DO concentration in the 545 aerobic zone 
Table 1 - Existing WWTP influent and effluent flow and concentration (annual average)

\begin{tabular}{|c|c|c|}
\hline & Influent & Effluent \\
\hline Flow rate $\left(\mathrm{m}^{3}\right.$ day $\left.^{-1}\right)$ & 5239 & \\
\hline Total COD $\left(\mathrm{mg} \mathrm{L}^{-1}\right)$ & 524 & 43 \\
\hline Soluble COD $\left(\mathrm{mg} \mathrm{L}^{-1}\right)$ & 204 & 32 \\
\hline $\mathrm{TN}\left(\mathrm{mg} \mathrm{L}^{-1}\right)$ & 37.3 & 24.7 \\
\hline $\mathrm{NH}_{4}-\mathrm{N}\left(\mathrm{mg} \mathrm{L}^{-1}\right)$ & 21 & 0.6 \\
\hline $\mathrm{NO}_{3}-\mathrm{N}\left(\mathrm{mg} \mathrm{L}^{-1}\right)$ & 0.1 & 21.3 \\
\hline $\mathrm{NO}_{2}-\mathrm{N}\left(\mathrm{mg} \mathrm{L}^{-1}\right)$ & 0.0 & 0.4 \\
\hline $\mathrm{TP}\left(\mathrm{mg} \mathrm{L}^{-1}\right)$ & 4.7 & 3.2 \\
\hline $\operatorname{TSS}\left(\mathrm{mg} \mathrm{L}^{-1}\right)$ & 267 & 7 \\
\hline
\end{tabular}


Table 2 - Set of simulations performed to assess the feasibility of the modified WWTP and preliminary design and optimize the MPC

\begin{tabular}{cccc}
\hline Run & $\begin{array}{c}\text { SB (\% of influent } \\
\text { flowrate) }\end{array}$ & $\begin{array}{c}\mathrm{AV}(\% \text { of } \\
\text { anoxic volume })\end{array}$ & $\begin{array}{c}\text { DO in aerobic fraction } \\
\text { of } \mathrm{MPC}\left(\mathrm{mg} \mathrm{L}^{-1}\right)\end{array}$ \\
\hline $001-011$ & $0-50$ & 0 & - \\
$101-188$ & $0-50$ & $9.8-78.2$ & 2 \\
$201-207$ & 30 & 39.1 & $0.01-2$ \\
& & \\
SB = Sludge Bypass; AV = Aerobic Volume; $\mathrm{DO}=$ Dissolved Oxygen
\end{tabular}

$\mathrm{SB}=$ Sludge Bypass; AV = Aerobic Volume; DO = Dissolved Oxygen 
Table 3 - Model parameters adjustment

\begin{tabular}{lcc}
\hline Model Parameter & $\begin{array}{c}\text { Default } \\
\text { value }\end{array}$ & Adjusted \\
\hline OHO anoxic yield & 0.54 & 0.90 \\
P in biomass AOB, NOB, OHO $\left({\left.\mathrm{mgP} \mathrm{mCOD}^{-1}\right)}^{0.022}\right.$ & 0.012 \\
P in endogenous residue $\left(\mathrm{mgP} \mathrm{mgCOD}^{-1}\right)$ & 0.022 & 0.012 \\
AOB maximum specific growth rate $\mu\left(\mathrm{d}^{-1}\right)$ & 0.9 & 0.5 \\
AOB half-saturation coefficient $\mathrm{K}_{\mathrm{N}}\left(\mathrm{mgN} \mathrm{L}^{-1}\right)$ & 0.7 & 1.0 \\
\hline
\end{tabular}

$\mathrm{OHO}=$ Ordinary Heterotrophic Organisms; AOB = Ammonia Oxidizer Bacteria; $\mathrm{NOB}=$ Nitrite Oxidizer Bacteria 
Table 4 - Simulated overall effluent quality, MPC effluent concentration of nitrate, and TSS concentration in the modified treatment train

\begin{tabular}{|c|c|c|c|c|c|c|c|c|c|c|c|}
\hline & \multirow[b]{2}{*}{$\begin{array}{l}\text { SB } \\
(\%)\end{array}$} & \multicolumn{3}{|c|}{ Total suspended solids $\left(\mathrm{mg} \mathrm{L}^{-1}\right)$} & \multicolumn{6}{|c|}{ Overall effluent $\left(\mathrm{mg} \mathrm{L}^{-1}\right)$} & \multirow{2}{*}{$\begin{array}{c}\begin{array}{c}\text { MPC effluent } \\
\left(\mathrm{mg} \mathrm{L}^{-1}\right)\end{array} \\
\qquad \mathrm{NO}_{3}-\mathrm{N}\end{array}$} \\
\hline & & $\begin{array}{c}\text { Anaerobic } \\
\text { zone }\end{array}$ & $\begin{array}{c}\text { Anoxic } \\
\text { zone }\end{array}$ & $\begin{array}{l}\text { Hybrid } \\
\text { trickling } \\
\text { filter }\end{array}$ & $\begin{array}{l}\text { Total } \\
\text { COD }\end{array}$ & $\begin{array}{c}\text { Soluble } \\
\text { COD }\end{array}$ & $\mathrm{TN}$ & $\mathrm{NH}_{4}-\mathrm{N}$ & $\mathrm{NO}_{3}-\mathrm{N}$ & $\mathrm{TP}$ & \\
\hline Run001 & 0 & 1959 & 2798 & 90 & 34.8 & 30.3 & 9.5 & 2.9 & 4.5 & 3.2 & 0.07 \\
\hline Run002 & 5 & 1838 & 2615 & 195 & 35.3 & 30.8 & 9.4 & 2.9 & 4.4 & 3.2 & 0.05 \\
\hline Run004 & 15 & 1950 & 2784 & 270 & 36.2 & 30.2 & 10.6 & 4.5 & 3.9 & 3.2 & 0.04 \\
\hline Run005 & 20 & 2001 & 2861 & 307 & 36.7 & 30.0 & 11.2 & 5.4 & 3.6 & 3.2 & 0.03 \\
\hline Run006 & 25 & 2007 & 2869 & 338 & 37.3 & 30.0 & 11.6 & 6.0 & 3.5 & 3.2 & 0.03 \\
\hline Run009 & 40 & 1908 & 2721 & 403 & 39.0 & 30.6 & 11.9 & 6.5 & 3.2 & 3.1 & 0.02 \\
\hline Run010 & 45 & 1860 & 2649 & 417 & 39.6 & 30.9 & 12.0 & 6.6 & 3.2 & 3.1 & 0.02 \\
\hline Run011 & 50 & 1810 & 2572 & 430 & 40.2 & 31.2 & 12.0 & 6.6 & 3.1 & 3.1 & 0.02 \\
\hline
\end{tabular}


TF - 1st stage

s

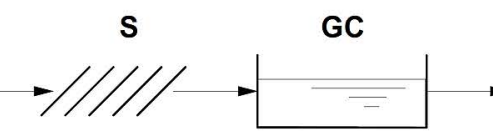

S: Screen

GC: Grit chamber

PC: Primary clarifier

IC: Intermediate clarifier

SC: Secondary clarifier

SW: Sludge waste

TF: Trickling filter
TF - 2nd stage
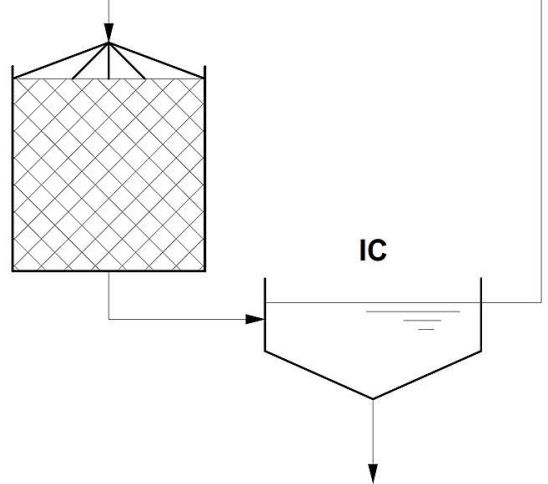

sw

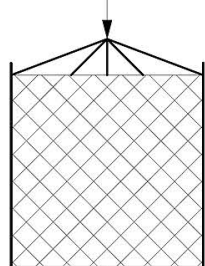

$\mathrm{SC}$

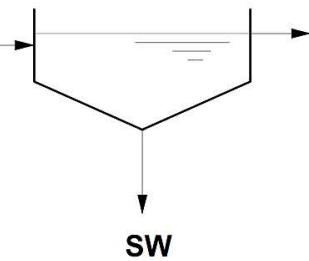




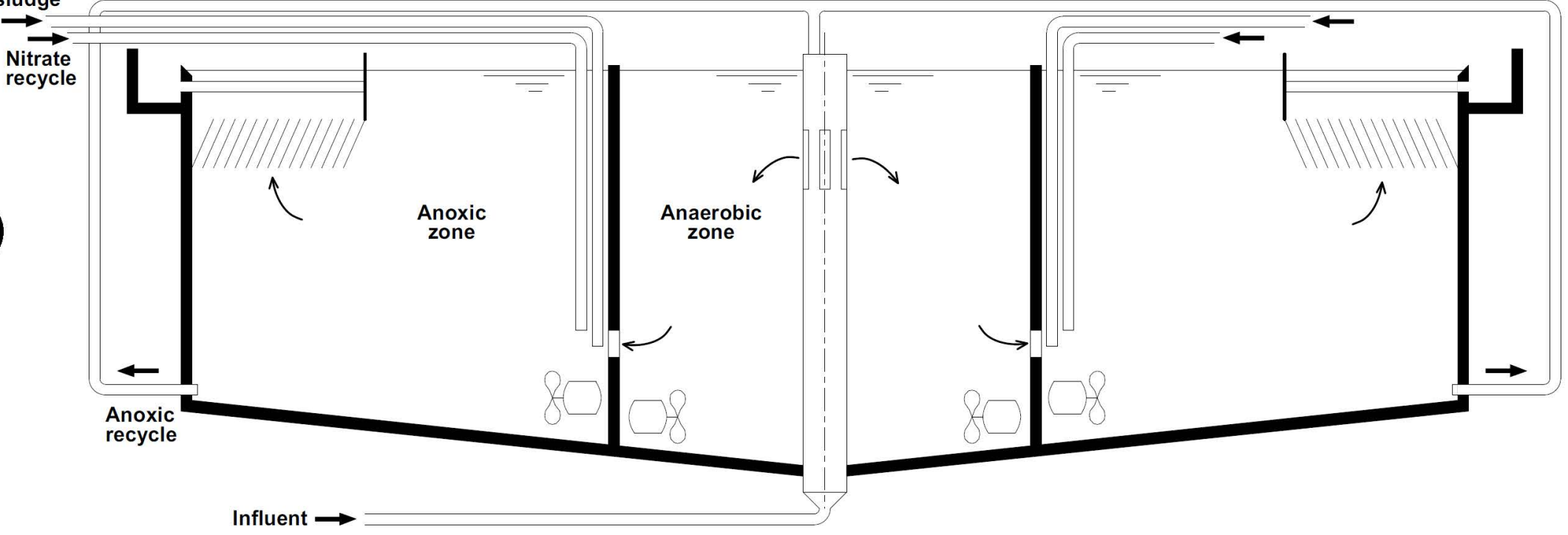

(B)

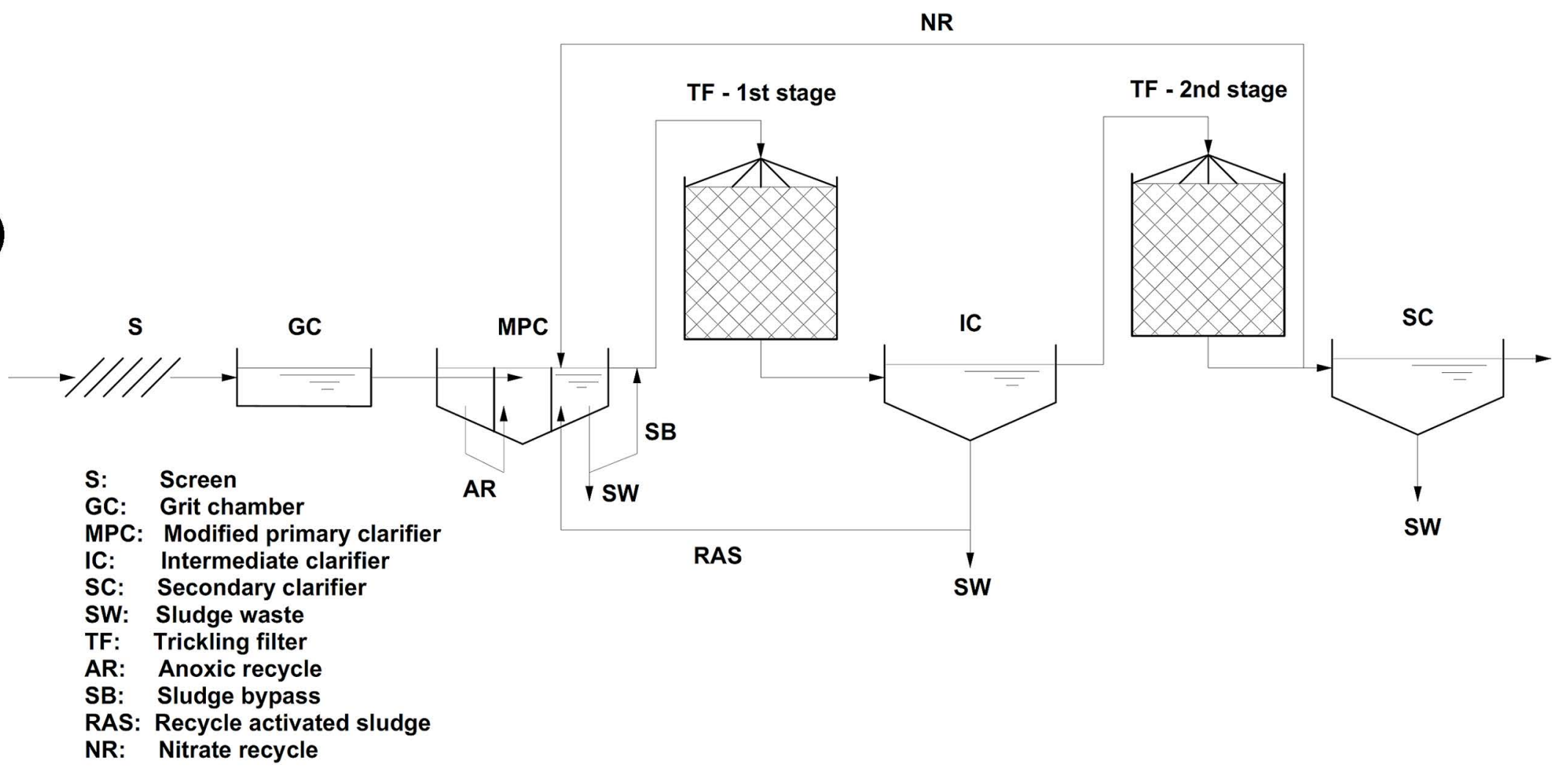




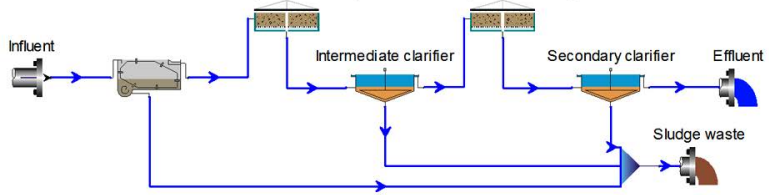

(B)

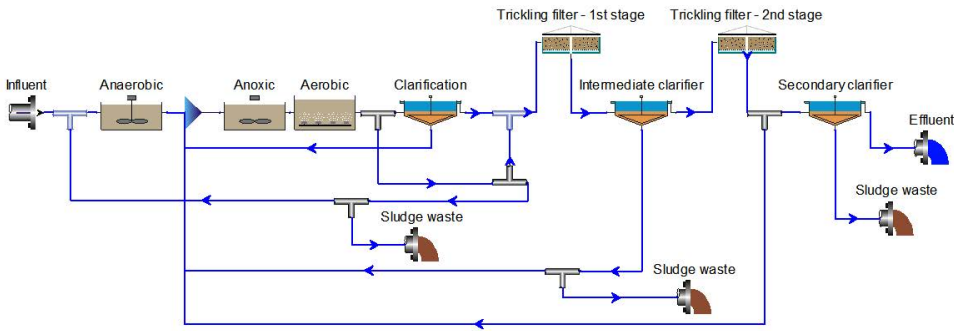




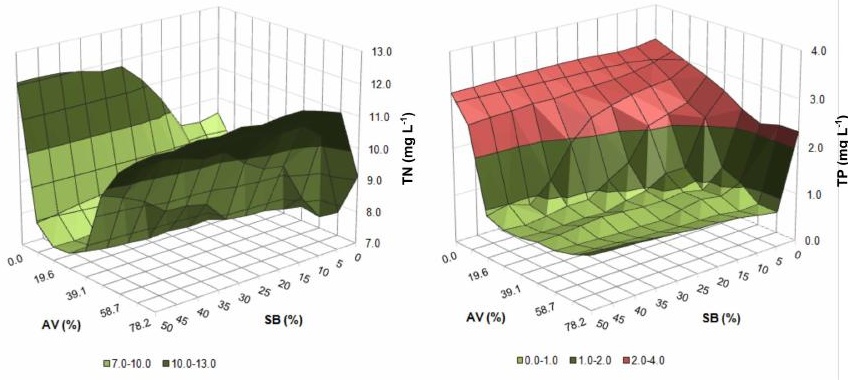




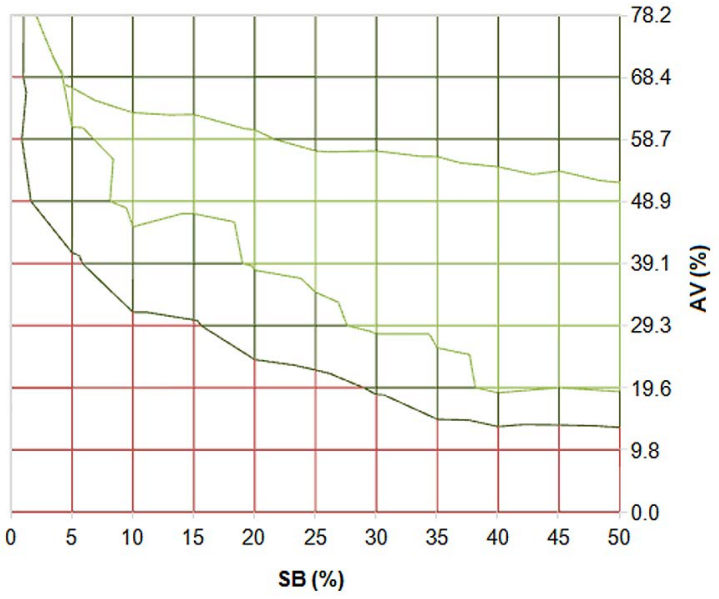


